OPEN ACCESS

Edited by:

Ilan Bank,

Sheba Medical Center, Israel

Reviewed by:

Emmanuel Scotet,

Institut National de la Santé et de la

Recherche Médicale

(INSERM), France

Zsolt Sebestyen,

University Medical Center

Utrecht, Netherlands

*Correspondence:

Mary Poupot

mary.poupot@inserm.fr

Specialty section:

This article was submitted to

T Cell Biology,

a section of the journal

Frontiers in Immunology

Received: 01 April 2020

Accepted: 01 June 2020

Published: 07 July 2020

Citation:

Laplagne C, Meddour S, Figarol S,

Michelas M, Calvayrac O, Favre G, Laurent C, Fournié J-J, Cabantous $S$ and Poupot M (2020) V $\gamma 9 \mathrm{~V} \delta 2 \mathrm{~T}$ Cells Activation Through Phosphoantigens

Can Be Impaired by a RHOB

Rerouting in Lung Cancer.

Front. Immunol. 11:1396.

doi: 10.3389/fimmu.2020.01396

\section{Vy9V82 T Cells Activation Through Phosphoantigens Can Be Impaired by a RHOB Rerouting in Lung Cancer}

\author{
Chloé Laplagne ${ }^{1,2,3}$, Sarah Meddour 1,2,3, Sarah Figarol ${ }^{1,2,3}$, Marie Michelas ${ }^{1,2,3}$, \\ Olivier Calvayrac ${ }^{1,2,3}$, Gilles Favre ${ }^{1,2,3,4}$, Camille Laurent ${ }^{1,2,3,4}$, Jean-Jacques Fournié ${ }^{1,2,3}$, \\ Stéphanie Cabantous ${ }^{1,2,3}$ and Mary Poupot ${ }^{1,2,3 *}$
}

${ }^{1}$ Centre de Recherches en Cancérologie de Toulouse, Inserm UMR1037, Toulouse, France, ${ }^{2}$ Université Toulouse III Paul-Sabatier, Toulouse, France, ${ }^{3}$ ERL 5294 CNRS, Toulouse, France, ${ }^{4}$ IUCT-O, Toulouse, France

V $\gamma 9 \mathrm{~V} \delta 2 \mathrm{~T}$ cells are known to be efficient anti-tumor effectors activated through phosphoantigens (PAg) that are naturally expressed by tumor cells or induced by amino bisphosphonates treatment. This PAg-activation which is TCR and butyrophilin BTN3A dependent can be modulated by NKG2D ligands, immune checkpoint ligands, adhesion molecules, and costimulatory molecules. This could explain the immuneresistance observed in certain clinical trials based on $\mathrm{V} \gamma 9 \mathrm{~V} \delta 2 \mathrm{~T}$ cells therapies. In NSCLC, encouraging responses were obtained with zoledronate administrations for $50 \%$ of patients. According to the in vivo results, we showed that the in vitro $\mathrm{V} \gamma 9 \mathrm{~V} \delta 2 \mathrm{~T}$ cell reactivity depends on the NSCLC cell line considered. If the PAg-pretreated KRAS mutated A549 is highly recognized and killed by $\vee \gamma 9 \mathrm{~V} \delta 2 \mathrm{~T}$ cells, the EGFR mutated PC9 remains resistant to these killers despite a pre-treatment either with zoledronate or with exogenous BrHPP. The immune resistance of PC9 was shown not to be due to immune checkpoint ligands able to counterbalance NKG2D ligands or adhesion molecules such as ICAM-1 highly expressed by PC9. RHOB has been shown to be involved in the $\mathrm{V} \gamma 9 \mathrm{~V} \delta 2$ TCR signaling against these NSCLC cell lines, in this study we therefore focused on its intracellular behavior. In comparison to a uniform distribution of $\mathrm{RHOB}$ in endosomes and at the plasma membrane in A549, the presence of large endosomal clusters of RHOB was visualized by a split-GFP system, suggesting that $\mathrm{RHOB}$ rerouting in the $\mathrm{PC9}$ tumor cell could impair the reactivity of the immune response.

Keywords: RHOB, $\mathrm{V}_{\gamma} 9 \mathrm{~V} \delta 2 \mathrm{~T}$ cells, phosphoantigen, endosomes, split-GFP, TCR activation

\section{INTRODUCTION}

Gamma delta $(\gamma \delta)$ T lymphocytes expressing the T cell receptor (TCR) $\mathrm{V} \gamma 9 \mathrm{~V} \delta 2$ are a prominent $\gamma \delta \mathrm{T}$ cell subset in human peripheral blood representing 1-3\% of blood mononuclear cells. Upon activation with non-peptide phosphoantigens (PAgs), these $\mathrm{V} \gamma 9 \mathrm{~V} \delta 2 \mathrm{~T}$ cells proliferate, produce chemokines and cytokines, and mediate cell cytotoxicity against a large spectrum of tumor cells (1). These molecules are metabolites from the methyl erythritol phosphate pathway in microbial pathogens (2) and from the eukaryotic mevalonate pathway in tumor cells which are thus spontaneously recognized and killed by $\mathrm{V} \gamma 9 \mathrm{~V} \delta 2 \mathrm{~T}$ cells $(3,4)$. In humans, treatment with aminobisphosphonates such as zoledronate can exacerbate $\mathrm{V} \gamma 9 \mathrm{~V} \delta 2 \mathrm{~T}$ cell reactivity through 
the upregulation of the endogenous biosynthesis of PAgs in mammalian cells (5). This PAgs activation was clearly shown to be TCR-dependent. However, as V $\gamma 9 \mathrm{~V} \delta 2 \mathrm{~T}$ cells express different activator and inhibitor receptors such as immune checkpoint inhibitors and natural killer (NK) receptors, their reactivity can also be exacerbated or curbed by ligands expressed by target cells $(6,7)$. Thus, even overproduction of endogenous PAgs might reflect the metabolic biases of cancer cells, and presumably occurs in most if not all types of tumors, some of which are resistant to V $\gamma 9$ V $\delta 2$ T killing. Accordingly, tumor-infiltrating $\gamma \delta \mathrm{T}$ cells have been detected in several solid and hematopoietic malignancies but are not always correlated with a good prognosis $(8,9)$. However, these cells remain very attractive candidates for cancer immunotherapies regarding a tumor regression associated with their significant amplification in the blood for some clinical trials based on PAg treatment or adoptive transfers of $\mathrm{V} \gamma 9 \mathrm{~V} \delta 2 \mathrm{~T}$ cells (10-12). In patients with non-small cell lung cancer (NSCLC), administration of zoledronate was correlated with an increase of $\mathrm{V} \gamma 9 \mathrm{~V} \delta 2 \mathrm{~T}$ cells in blood and a higher overall survival (13). A phase I clinical study showed the safety and potential antitumor effect of reinfused ex-vivo expanded V $\gamma 9 \mathrm{~V} \delta 2 \mathrm{~T}$ cells in patients with advanced NSCLC refractory to or intolerant to current conventional treatment (14). These partial responses and the inevitable relapse with classical treatments make NSCLC incurable pathologies for which many mechanisms of acquired resistance have been elucidated, but the recurrent immuneresistance remains obscure. $\mathrm{RHOB}$ is a known tumor suppressor in lung cancer, and its downregulation, frequently observed in aggressive tumors (15), is associated with decreased overall survival (16). More recently, $\mathrm{RHOB}$ has also been shown to confers resistance to EGFR-tyrosine kinase inhibitors in NSCLC (17), suggesting different roles of this GTPase depending on the oncogenic and/or therapeutic context. Interestingly, RHOB was recently shown to mediate endogenous $\mathrm{PAg}$ recognition by the V $\gamma 9$ V82 TCR (18). RHOB interaction with endogenous PAg in the target cell could induce a modification of the conformation of the membrane butyrophilin BTN3A1 which then activates the V $\gamma 9$ V82 TCR (19). Here, we investigated the role of RHOB in the response to PAg-mediated $\gamma \delta \mathrm{T}$ cell activation in two NSCLC cell lines with the most represented oncogenic mutations KRAS and EGFR. After showing that A549 was well-recognized and killed by $\mathrm{V} \gamma 9 \mathrm{~V} \delta 2 \mathrm{~T}$ cells compared to PC9, we found different patterns of surface molecule expression for these two NSCLC cell lines. However, the resistance of PC9 to $\mathrm{V} \gamma 9 \mathrm{~V} \delta 2 \mathrm{~T}$ cell killing could be due to a rerouting of RHOB in late/degradation compartments that may prevent its function with BTN3A1 at the plasma membrane in PC9 cells.

\section{MATERIALS AND METHODS}

\section{Reagents and Antibodies}

Antibodies for flow cytometry analysis: BV310 anti-CD3, FITC anti-TCRV $\gamma$ 9V82, PE or PeCy5 anti-CD107a, PeCy7 anti-IFN $\gamma$, PE anti-TIM3, PE anti-Galectin9, PeCy7 anti-PD1, APC antiPDL1, PeCy5 anti-CD80, PE anti-CD80, PeCy5 anti-HLAABC, AF647 anti-CD31, PeCy7 anti-CD38, FITC anti-CD226, FITC anti-CD112, FITC anti-CD155, PE anti-LFA1, and isotype controls (BD Biosciences, Pont de Claix, France); BV421 antiCD69 and isotype control (Miltenyi Biotech, Paris, France); PE anti-HLAE (eBiosciences); PE anti-ULPB2,5,6 (R\&D Systems, Minneapolis, USA); APC anti-MICA/B (Biolegend, St-Quentinen-Yvelines, France); PE anti-ICAM1 and PE anti-ICAM3 (Immunotech, Marseille, France); PE anti-LFA3 (Beckman Coulter, Fullerton, CA, USA).

Blocking antibodies: anti-BTN3A1 $1 \mathrm{~h}$ at $10 \mu \mathrm{g} / \mathrm{mL}(103.2$ clone, kindly gifted by ImCheck Therapeutics, Marseille, France), anti- $\gamma \delta$ TCR $1 \mathrm{~h}$ at $0.5 \mathrm{mg} / \mathrm{mL}$ (B1 clone, Biolegend), anti-ICAM1 (W-CAM-1 clone, Thermo fisher, Villebon sur Yvette, France) and anti-CD31 $1 \mathrm{~h}$ at $10 \mu \mathrm{g} / \mathrm{mL}$ (HEC7 clone, Thermo fisher, Villebon sur Yvette, France). The exoenzyme C3 transferase was used as RHO inhibitor I overnight at $2 \mu \mathrm{g} / \mathrm{mL}$ (Cytoskeleton, Inc. Denver, USA).

\section{Flow Cytometry Analysis}

Cells were labeled with $5 \mu \mathrm{g} / \mathrm{ml}$ antibodies or isotype controls for $20 \mathrm{~min}$ at $4^{\circ} \mathrm{C}$ and analyzed on an LSRII cytometer (BD Biosciences, Pont de Claix, France). Data were analyzed using BD FACSDiva software, FlowJo software or FlowLogic software.

\section{V $\gamma$ 9V82 T Cell Cultures}

Primary $\mathrm{V} \gamma 9 \mathrm{~V} \delta 2 \mathrm{~T}$ cell cultures were generated from peripheral blood mononuclear cells (PBMCs) isolated from blood of healthy donors (Etablissement Français du Sang, Toulouse, France). Briefly, PBMC were stimulated with BrHPP $(3 \mu \mathrm{M})$ and rhIL-2 (300 IU/ml) in complete RPMI 1640 culture medium (Invitrogen, Cergy Pontoise, France) supplemented with 10\% fetal calf serum (Hy1, Thermo Scientific, USA), $100 \mathrm{~g} / \mathrm{ml}$ streptomycin, $100 \mathrm{IU} / \mathrm{ml}$ penicillin and $1 \mathrm{mM}$ sodium-pyruvate (Cambrex Biosciences, Rockland, ME, USA) for 14 days. Purity of the V $\gamma 9 \mathrm{~V} \delta 2 \mathrm{~T}$ cells was $>95 \%$ as determined by flow cytometry using an anti-TCRV $\gamma 9 \mathrm{~V} \delta 2 \mathrm{mAb}$.

\section{Lung Cancer Cell Lines}

The human NSCLC cell lines A549, H1299, H827, and PC9 were previously obtained from the American Type Culture Collection (Manassas, VA, USA) and cultured in RPMI 1640 medium containing $10 \%$ fetal bovine serum (FBS) and were maintained at $37^{\circ} \mathrm{C}$ in a humidified chamber containing $5 \% \mathrm{CO}_{2}$.

For the RHOB KO A549 and PC9, the TALEN sequences targeting RHOB were designed by CELLECTIS (Paris, France), and inserted into two plasmids comprising CMV and T7 promoters. Triple transfection of the two TALEN-encoding plasmids with a Puromycin selection cassette upstream RHOB gene was performed using the JetPrime ${ }^{\circledR}$ transfection agent (Polyplus transfection) according to the manufacturer's recommendations. Puromycin selection was performed for $48 \mathrm{~h}$ after transfection and the pool of surviving clones was subcloned by limit dilution in 96-well plates. For each subclone, RHOB DNA levels and RHOB protein expression were analyzed by PCR and Western Blot.

\section{Cytotoxicity Assay}

Lung cancer cell lines were treated at $70 \%$ of confluence with $\operatorname{BrHPP}(1 \mu \mathrm{M}, 4 \mathrm{~h}$, Innate Pharma, Marseille, France) or 
Zoledronic acid monohydrate (Zometa, $5 \mu \mathrm{M}$, overnight, Sigma Aldrich, Saint Louis, USA). After washing, treated cancer cells were co-cultured in 96-wells plates with overnight IL-2-deprived V $\gamma 9$ V $82 \mathrm{~T}$ cells (E:T ratio 1:1) in complete medium with antiCD107a mAb or IgG1 control $(5 \mu \mathrm{g} / \mathrm{ml})$. Brefeldin A $(10 \mu \mathrm{g} / \mathrm{ml}$, Sigma Aldrich, St Quentin Fallavier, France) was added at $2 \mathrm{~h}$ of co-culture. After $4 \mathrm{~h}$ of co-culture cells were washed, stained and analyzed by flow cytometry. When mentioned, contact between $\gamma \delta \mathrm{T}$ cells and target cells was prevented thanks to a Transwell ${ }^{\circledR}$ system (Corning). For intracellular IFN $\gamma$ expression, cells were fixed with PBS $2 \%$ paraformaldehyde and permeabilized with PBS containing 5\% FCS and 1\% saponin (Sigma-Aldrich) prior to staining for $30 \mathrm{~min}$ with the specified $\mathrm{mAb}$ for flow cytometry analysis.

\section{Trogocytosis Analysis}

Lung cancer cells were stained with the lipophilic green-emitting dye PKH67 (Sigma-Aldrich, Saint Louis, USA) according to the manufacturer's instructions. Then, PKH67-positive cells were co-cultured for $4 \mathrm{~h}$ in complete culture medium with PKH67negative $\mathrm{V} \gamma 9 \mathrm{~V} \delta 2 \mathrm{~T}$ cells in 96-well U-bottom culture plates at a cell ratio of 1:1. After gentle centrifugation ( $110 \mathrm{~g}$ for $1 \mathrm{~min}$ ) and co-cultures for $3 \mathrm{~min}$ or $4 \mathrm{~h}$ at $37^{\circ} \mathrm{C}$, cells were washed with $0.5 \mathrm{mM}$ PBS/EDTA. Trogocytosis was measured as the acquisition of PKH67 fluorescence, which was characterized via the increase of the mean fluorescence intensity (mfi) of PKH67 by a flow cytometry.

\section{Monitoring RHOB Activity With a Split-GFP Reporter System}

To evaluate the effect of PAg, A549, and PC9 cell lines were engineered to express the tripartite split-GFP biosensor system previously developed to monitor RHOB activity in single cells (20). To generate the split-GFP reporter cell line, sequential transductions were performed with lentiviruses encoding for GFP1-9, the detector fragment of the split-GFP system and the chimeric construct that coexpress both $\mathrm{RHOB}$ fused to the strand 10 of trisfGFP (GFP10-RHOB) and the RHO-binding domain of Rhotekin (RBD) fused to strand 11 of trisfGFP (RBD-GFP11) in A549-rtTA or PC9-rtTA cells. After recovery, cells were induced with $0.25 \mu \mathrm{g} / \mathrm{mL}$ doxycycline for $24 \mathrm{~h}$ and sorted by FACS based on GFP fluorescence. To improve the GFP fluorescence signal upon split-GFP complementation, a GFP nanobody (21) was expressed from a lentiviral expression vector on optimized cell lines.

For both fluorescence quantifications of RHOB activity and analysis of RHOB localization, reporter cells were grown on $\mu$-Slide 8-well ibiTreat chambered coverslips (Ibidi, Biovalley). Cells were seeded at a density of 15,000 cells/well for PC9 and 35,000 cells/well for A549 for $24 \mathrm{~h}$. Split-GFP reporter expression was induced for $24 \mathrm{~h}$ with $0.25 \mu \mathrm{g} / \mathrm{ml}$ Doxycycline in RPMI culture medium supplemented with $2 \%$ serum (PC9) and $10 \%$ serum (A549), and subsequently treated with PAg for $16 \mathrm{~h}$ with Zoledronic acid monohydrate or $4 \mathrm{~h}$ of BrHPP. To stop the experiment, cells were fixed with 4\% PFA, PBS then stained with a cytoplasmic cell mask, HCS CellMaskTM Blue Stain (Thermo Fisher Scientific) according to the supplier's instructions. Quantitative image acquisition was performed using an Operetta high-content imaging system (Perkin Elmer) with a $20 \times$ objective lens in the $488 / 525 \mathrm{~nm}$ (GFP) and $360 / 405 \mathrm{~nm}$ (cell mask) channels. Analysis was performed with Harmony ${ }^{\circledR}$ software on an average of 1500 cells/well. The number of objects and the sum of cell area was determined from the cell mask staining. The percentage of GFP cells was calculated as: percentage GFP cells = (number of GFP-positive cells/number of all objects $) \times 100$, where GFP-positive cells are defined by cells following this criteria: mean of fluorescence intensity (MFI) of the object $>$ mean of MFI in the control wells without doxycycline. GFP intensity sum/cell area was defined as the (GFP intensity sum of GFP + cells)/(HCS intensity sum of GFP+ cells).

For confocal analysis, cells were fixed with 3.7\% PFA and permeabilized with $0.1 \%$ Triton X-100 in PBS buffer. Blocking was performed with $8 \%$ BSA, PBS for $30 \mathrm{~min}$ before adding primary antibodies. Anti-GFP10 polyclonal antibody (20) was used at 1:1,000 dilution for $1 \mathrm{~h}$, followed by secondary antibody Alexa fluor 594 conjugate anti rabbit IgG (Life technologies) for $40 \mathrm{~min}$. For labeling endosomes, the following primary antibodies were used: Rab7 [(D95F2) XP 9367, Cell signaling] 1:50, LAMP1 (H5G11) sc-18821, Santa Cruz Biotechnology 1:50. After overnight incubation, secondary antibodies were added Alexa fluor 594 conjugate anti rabbit IgG (Life technologies) and Alexa fluor 647 conjugate anti mouse IgG (Life technologies). Microscopy images were acquired using LSM 780 or LSM 880 (Zeiss, Oberkochen, Germany) confocal laser scanning microscopes using a 488 Argon laser with a 490-553 nm emission filter (GFP) Alexa 594 and DAPI labeling were acquired with Argon laser (543 nm) and $405 \mathrm{UV}$ diode lasers, respectively, using $20 \mathrm{x}$ and $63 \times / 1.4$ oil immersion objectives. Image analysis was performed with Image ${ }^{\circledR}$ software.

\section{Statistical Analysis}

Data are expressed as means \pm SEM. For comparison of two series of normally distributed variables, we used paired and onetailed Student's $t$-tests with $\alpha=0.05$ for statistical significance. Statistical analysis were performed with Prism software.

\section{RESULTS}

\section{Differential Activation of $\mathrm{V} \gamma \mathrm{gV} \delta 2 \mathrm{~T}$ Cells by Different PAg-Treated NSCLC Cell Lines}

To analyze the role of RHOB in $\mathrm{V} \gamma 9 \mathrm{~V} \delta 2 \mathrm{~T}$ cell reactivity against NSCLC, we first screened the basal reactivity of $\mathrm{V} \gamma 9 \mathrm{~V} \delta 2 \mathrm{~T}$ cells against four cell lines with different mutation statuses: A549 (KRAS mutant), H1299 (HRAS mutant), PC9 and H827 (EGFR mutant). The expression of CD107a and IFN $\gamma$ by $\mathrm{V} \gamma 9 \mathrm{~V} \delta 2 \mathrm{~T}$ cells after co-cultures with the different tumor cell lines was measured by flow cytometry. Compared to the Daudi control target cells, which induced CD107a and IFN $\gamma$ expression by $\mathrm{V} \gamma 9 \mathrm{~V} \delta 2 \mathrm{~T}$ cells, no basal reactivity was detected with the four NSCLC cell lines (Figures 1A,B black dots). However, incubation of these cell lines with zoledronate (red dots) or with an exogenous synthetic PAg, BrHPP (blue dots), induced a high increase of the percentage of IFN $\gamma$ and CD107a positive $\mathrm{V} \gamma 9 \mathrm{~V} 82 \mathrm{~T}$ cells in co-culture with A549, H827, and H1299 but 
not with PC9 (Figure 1B). We then checked that this reactivity was due to an immunological synapse following a contact between $\mathrm{V} \gamma 9 \mathrm{~V} \delta 2 \mathrm{~T}$ cells and NSCLC target cells and not to PAg excreted in the co-culture medium. $\mathrm{V} \gamma 9 \mathrm{~V} \delta 2 \mathrm{~T}$ cells were thus incubated for $4 \mathrm{~h}$ with A549 or PC9, previously treated with PAg, and separated by a Transwell (TW) membrane or with their conditioned medium. As shown in Figure 1C, no CD107a expression was detected in $\mathrm{V} \gamma 9 \mathrm{~V} \delta 2 \mathrm{~T}$ cells in the TW condition or in the conditioned medium condition (CM) (Figure 1C for a representative experiment and Supplementary Figure $\mathbf{1}$ for pooled experiments). Trogocytosis was also evaluated to confirm the contact dependent reactivity of $\mathrm{V} \gamma 9 \mathrm{~V} \delta 2 \mathrm{~T}$ cells against A549. Trogocytosis is the transfer of membrane patches following the establishment of an immunological synapse between a $\mathrm{T}$ lymphocyte and a target cell. The membrane transfer was measured by the increase of green (PKH67) fluorescence expressed by the $\mathrm{V} \gamma 9 \mathrm{~V} \delta 2 \mathrm{~T}$ following contact with the A549 cell line previously stained with the PKH67 fluorescent probe stably inserted into the plasma membrane. $\mathrm{V} \gamma 9 \mathrm{~V} \delta 2 \mathrm{~T}$ cells expressed PKH67 fluorescence after $4 \mathrm{~h}$ of contact with PAgtreated $\mathrm{PKH}_{67}{ }^{+} \mathrm{A} 549$ compared to $5 \mathrm{~min}$ of contact (Figure 1D for a representative experiment and Supplementary Figure 2 for pooled experiments). CD107a and IFN $\gamma$ expression by $\mathrm{V} \gamma 9 \mathrm{~V} 82 \mathrm{~T}$ cells, and their trogocytosis in reaction to A549 were correlated with the death of A549 (Figure 1E and Supplementary Figure 3A). On the contrary, PC9, even treated by phosphoantigens was relatively resistant to $\mathrm{V} \gamma 9 \mathrm{~V} \delta 2 \mathrm{~T}$ cell killing (Figure 1F and Supplementary Figure 3B).

V 9 V 82 T cells can thus be highly activated to kill A549 but not PC9, when previously treated with phosphoantigens.

\section{Expression of Different Patterns of Surface Ligands and Adhesion Molecules on A549 and PC9}

The immunological synapse between $\mathrm{V} \gamma 9 \mathrm{~V} \delta 2 \mathrm{~T}$ cells and tumor cells involves different surface molecules such as activator and inhibitor ligands/receptors, and adhesion molecules. Expression of these molecules at the surface of A549, PC9, and the V $\gamma 9 \mathrm{~V} \delta 2 \mathrm{~T}$ cells was performed by flow cytometry analysis. With regard to the adhesion molecule pattern, LFA-1, LFA-3, and CD155 were expressed at the same level by A549 and PC9 whilst ICAM3, CD112, CD31, and the costimulatory ligands CD80/CD86 were not expressed (Figure 2A and Supplementary Figure 4A). However, PC9 expressed high levels of the adhesion molecule ICAM-1 compared to A549, and A549 expressed high level of CD38 compared to PC9. The corresponding receptors were checked at the surface of $\mathrm{V} \gamma 9 \mathrm{~V} \delta 2 \mathrm{~T}$ cells which thus expressed LFA-1, ICAM-1, ICAM-3, CD2, LFA-3, CD226, CD38, and CD31 (Figure 2B). Considering the activator and inhibitor ligands, A549 expressed less ULBPs and PDL1 than PC9 but more HLA-A,B,C whereas MICA/B and galectin-9 were not expressed neither by A549 nor by PC9 (Figure 2A), V $\gamma 9 \mathrm{~V} \delta 2 \mathrm{~T}$ cells expressed the corresponding receptors NKG2A, NKG2D, PD1, and Tim-3 (Figure 2B). The level of expression of all these ligands/receptors on A549 and PC9 were not statistically affected by PAg treatment (Supplementary Figure 4B). We then investigated which surface molecules were involved in $\mathrm{V} \gamma 9 \mathrm{~V} \delta 2 \mathrm{~T}$ cell activation using blocking antibodies. We showed that blocking the LFA-3/CD2 axis decreased IFN $\gamma$ expression by V $\gamma 9$ V $82 \mathrm{~T}$ cells in contact with A549 pretreated either with zoledronate or with BrHPP whilst blocking ICAM-1/LFA-1 or CD31/CD38 had no effect (Figure 2C). On the contrary, the weak $\mathrm{V} \gamma 9 \mathrm{~V} \delta 2 \mathrm{~T}$ cell activation by PC9 was decreased at the level of the ICAM-1/LFA-1 axis, whilst blocking of LFA-3/CD2 and of CD31/CD38 had no effect (Figure 2D). Moreover, neither the blocking of NKG2D nor PD1 had an impact on $\mathrm{V} \gamma 9 \mathrm{~V} \delta 2 \mathrm{~T}$ cell activation by $\mathrm{A} 549$ or PC9.

Finally, A549 and PC9 displayed different patterns of surface ligands and adhesion molecules and involved different surface molecules in PAg-dependent activation of $\mathrm{V} \gamma 9 \mathrm{~V} \delta 2 \mathrm{~T}$ cells. However, these differences cannot be sufficient to explain the different activation of V $\gamma 9 \mathrm{~V} \delta 2 \mathrm{~T}$ cells by PC 9 compared to A549. Indeed, PC9 expresses a high proportion of the inhibitory PDL1 and a high amount of ICAM-1 and ULBPs which are supposed to favor a productive immunological synapse. Conversely, A549 expresses CD38 but also expresses the inhibitory ligand HLAA,B,C and a weak amount of ULBPs.

As the difference in surface markers of the two NSCLC cell lines did not explain the difference in $\mathrm{V} \gamma 9 \mathrm{~V} \delta 2 \mathrm{~T}$ cells activation, we decided to explore inside the cells.

\section{RHOB Deletion in PAg-Treated A549 Cell Lines Decreases $\mathrm{V}_{\gamma} \mathbf{9} \mathbf{V} \boldsymbol{\delta} \mathbf{2} \mathrm{T}$ Cell Activation}

BTN3A1 was previously shown to be involved in $\mathrm{V} \gamma 9 \mathrm{~V} \delta 2 \mathrm{~T}$ cell TCR-dependent activation. BTN3A1 may interact with the V 99 V 22 TCR upon association with RHOB activated by its interaction with endogenous phosphoantigens (18). Thus, we investigated the role of $\mathrm{RHOB}$ in $\mathrm{V} \gamma 9 \mathrm{~V} \delta 2 \mathrm{~T}$ cell activation by these NSCLC cell lines. Firstly, A549 and PC9 cell lines were shown to express BTN3A1 at the transcriptomic and protein level (Figures 3A,B). Interestingly, PAg treatment of these cell lines had no impact on their BTN3A1 expression. We then determined whether $\mathrm{V} \gamma 9 \mathrm{~V} \delta 2 \mathrm{~T}$ cell activation by zoledronateor BrHPP-treated NSCLC cell lines was BTN3A1-dependent using a blocking antibody (103.2 clone). The percentage of V $\gamma 9$ V82 T cells expressing IFN $\gamma$, CD107a and CD69 following contact with BrHPP- or zoledronate-treated A549 was highly decreased by the presence of anti-BTN3A1 during the co-culture (Figure 3C for a representative experiment and Figure 3D for pooled experiments). BTN3A1 blocking also abrogated the weak activation of $\mathrm{V} \gamma 9 \mathrm{~V} \delta 2 \mathrm{~T}$ cells by the PC9 cell line (Figure 3E for a representative experiment and Figure $3 \mathrm{~F}$ for pooled experiments). Thus, the high activation of $\mathrm{V} \gamma 9 \mathrm{~V} \delta 2 \mathrm{~T}$ cells by PAg-treated A549 and the weak activation by PAg-treated PC9 are totally dependent on BTN3A1. As RHOB has been implicated in the regulation of the immune response through BTN3A1 modulation (18), we studied the implication of this GTPase in $\mathrm{V} \gamma 9 \mathrm{~V} \delta 2 \mathrm{~T}$ cell activation by NSCLC cell lines. RHOB was knocked out in the A549 and PC9 cell lines by the TALEN gene silencing method (Supplementary Figure 5). We then assessed the effect of this knockdown (KO) on $\mathrm{V} \gamma 9 \mathrm{~V} \delta 2 \mathrm{~T}$ cell activation by measuring IFN $\gamma$ and CD107a expression, and trogocytosis 


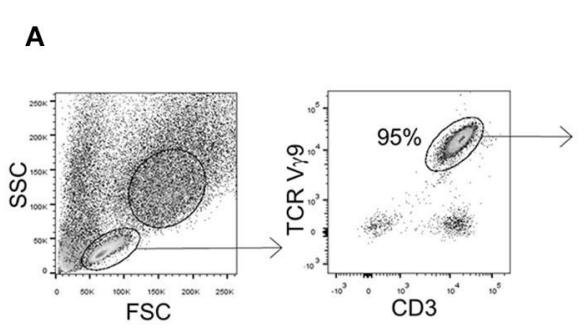

B Vy9Vס2 T cells expressing IFNy (\%)

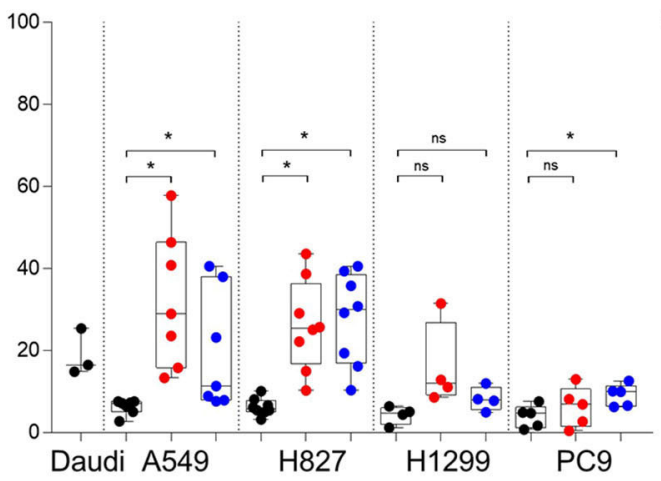

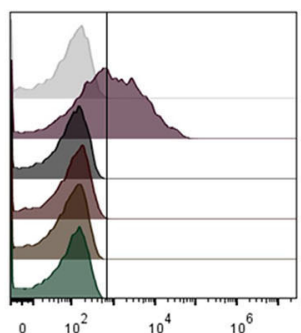

IFNy mfi

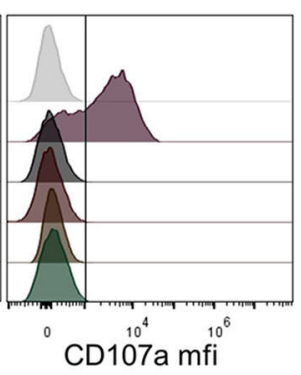

Ig

Daudi

A549

$\mathrm{H} 827$

H1299

PC9

Vy9Vס2 T cells expressing CD107a (\%)

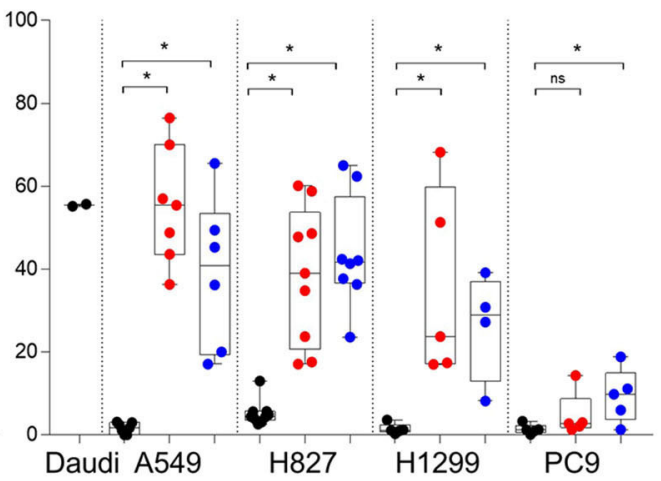

C
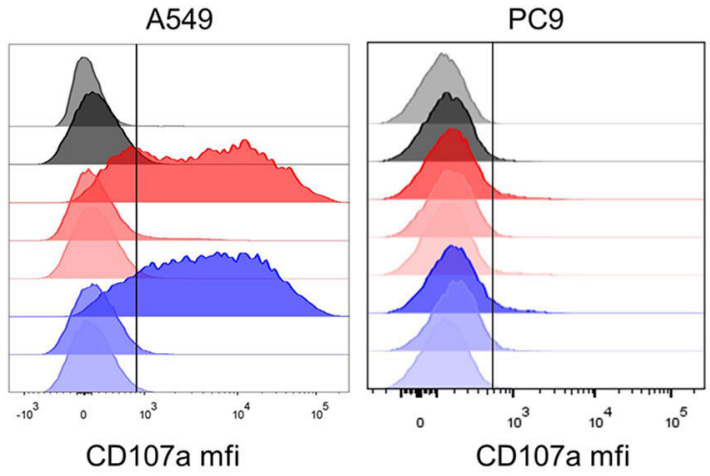

UT

Zol

Zol TW

Zol CM

BrHPP

BrHPP TW

BrHPP CM

D

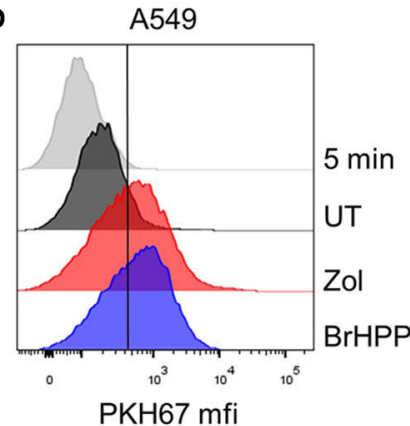

E

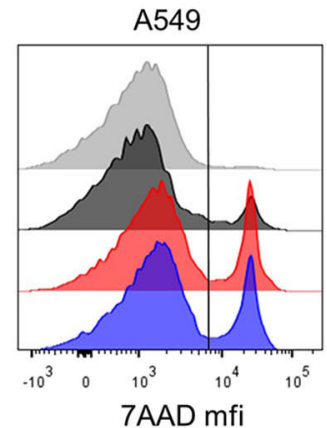

F

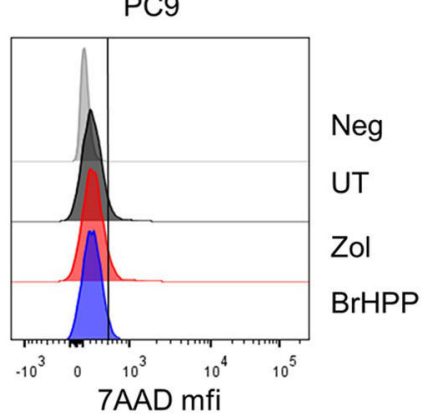

FIGURE 1 | PAg-treated NSCLC cell lines activate $\mathrm{V} \gamma 9 \mathrm{~V} \delta 2 \mathrm{~T}$ cells in a contact dependent manner. Flow cytometry analysis of the IFN $\gamma$ and CD107a expression by $\mathrm{V} \gamma 9 \mathrm{~V} \delta 2 \mathrm{~T}$ cells in co-culture for $4 \mathrm{~h}$ with four different NSCLC cell lines without pretreatment (A) or with zoledronate (red dots) or BrHPP (blue dots) pretreatment [(B), $n>4$ independent experiments], with Transwell system or tumor cell lines conditioned medium in case of A549 and PC9 as target (C). Flow cytometry analysis of the trogocytosis of the PKH67+ PAg-treated A549 cell line by the $\mathrm{V} \gamma 9 \mathrm{~V} \delta 2 \mathrm{~T}$ cells after $5 \mathrm{~min}$ or $4 \mathrm{~h}$ of co-culture, i.e., PKH67 expression by the $\mathrm{V} \gamma 9 \mathrm{~V} \delta 2 \mathrm{~T}$ cells (D). Measure by flow cytometry of the 7-AAD positive PAg-treated-A549 (E) or -PC9 (F) after co-culture with $\mathrm{V} \gamma 9 \mathrm{~V} \delta 2 \mathrm{~T}$ cells for $4 \mathrm{~h}$. *indicates $p<0.05$, Student's paired t-test; ns: no significant. 


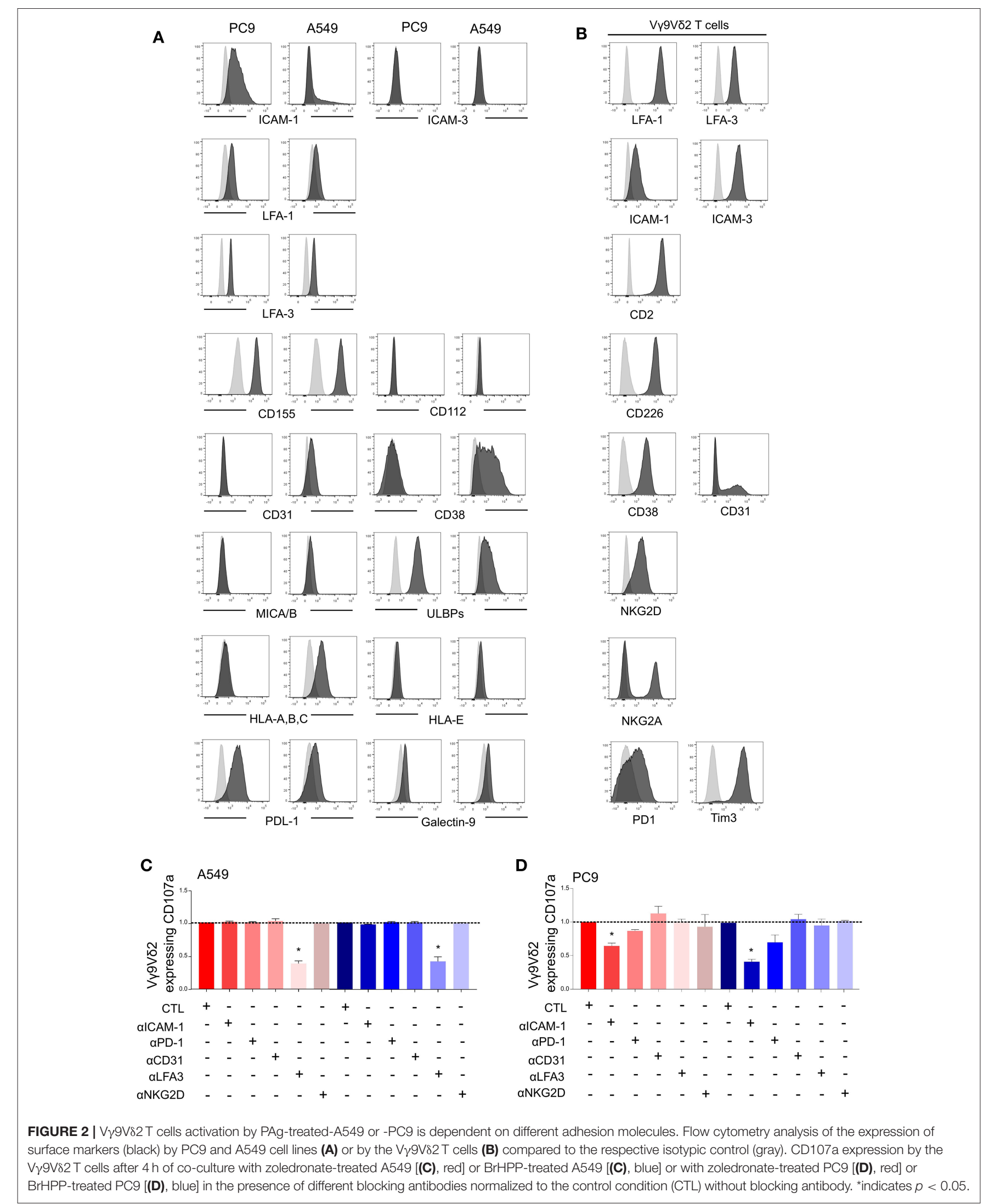


A

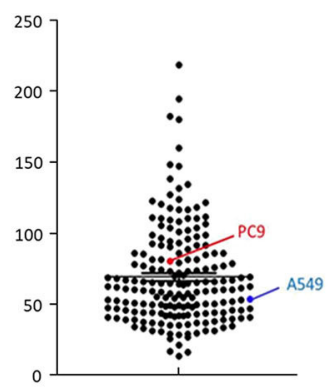

B

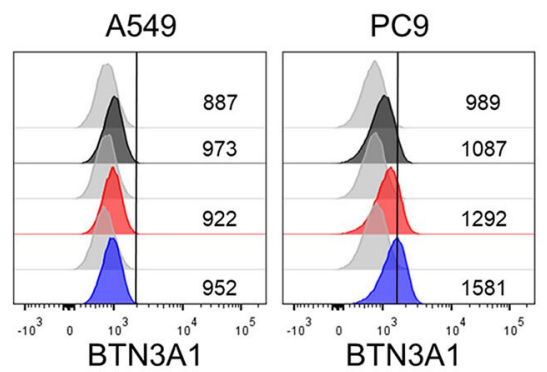

C

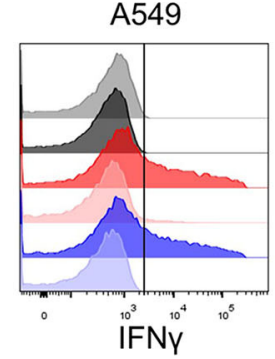

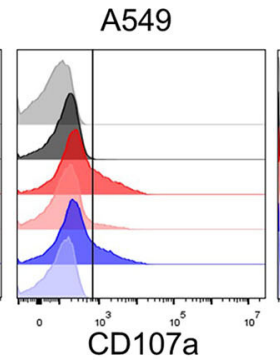

A549
A549

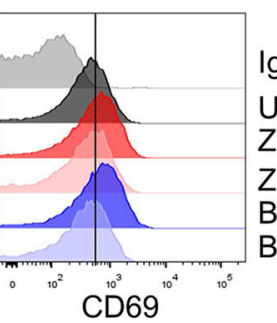

$\lg$

UT

Zol

Zol + aBTN3A1

BrHPP

$\mathrm{BrHPP}+\alpha \mathrm{BTN} 3 \mathrm{~A} 1$
D $\quad \mathrm{Y}$ 9 $\mathrm{V} \delta 2 \mathrm{~T}$ cells expressing IFNy (\%)
Vy9Vठ2 T cells expressing CD107a (\%)
Vү9V $\delta 2$ T cells expressing CD69 (\%)
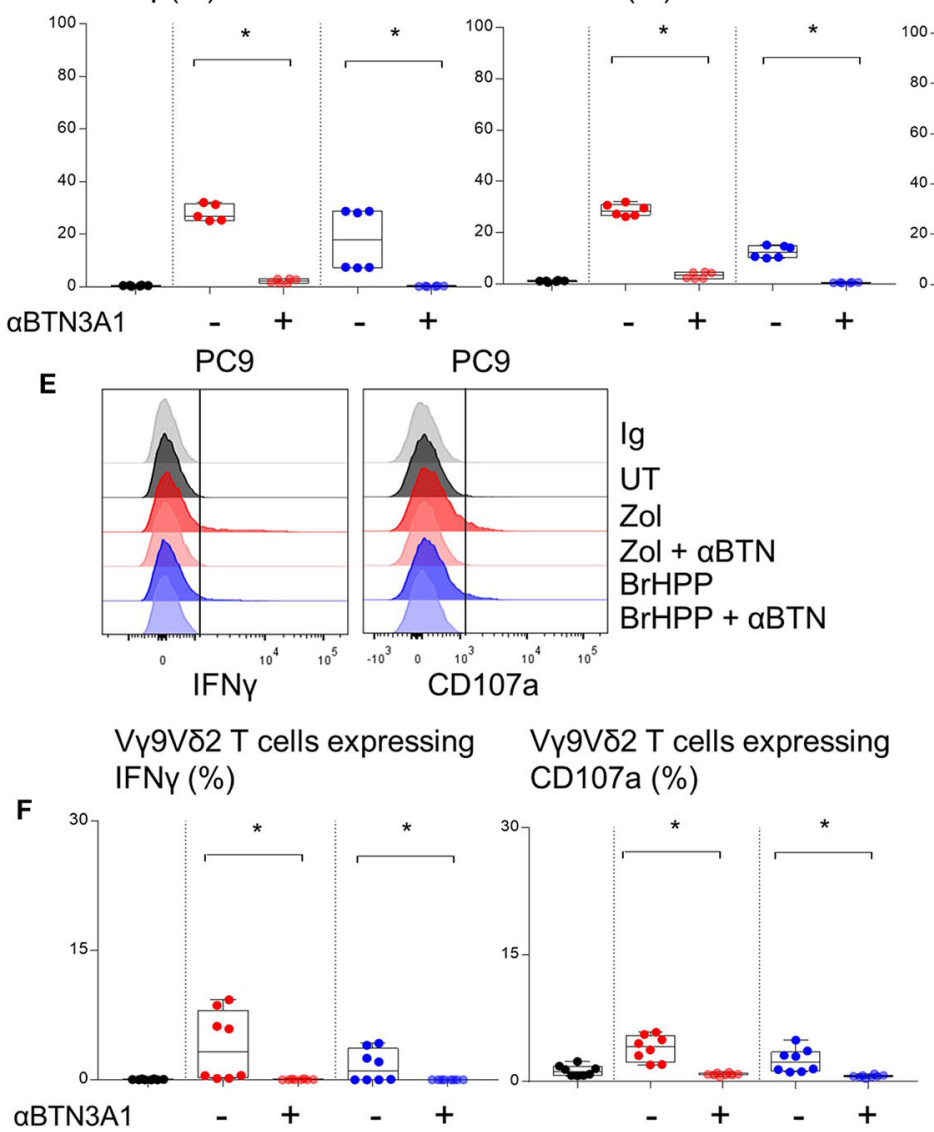

FIGURE 3 | PAg-treated A549/PC9 cell lines activating Vy9V82T cells is BTN3A1 dependent. (A) mRNA expression of the BTN3A1 by A549 and PC9 cell lines among cancer cell lines in the Cancer Cell Line Encyclopedia (CCLE). (B) Flow cytometry analysis of the BTN3A1 expression by A549 and PC9 pre-treated or not (black) by zoledronate (red) or BrHPP (blue) and compared to the isotypic control (gray). (C-F) Flow cytometry analysis of the IFN $\gamma$, CD107a, and CD69 expression by V $\gamma 9$ V $82 \mathrm{~T}$ cells in co-culture for $4 \mathrm{~h}$ with A549 [(C,D): six independent experiments] or PC9 [(E,F): six independent experiments] without pretreatment (black) or with zoledronate (red) or BrHPP (blue) pretreatment. "indicates $p<0.05$. 
A

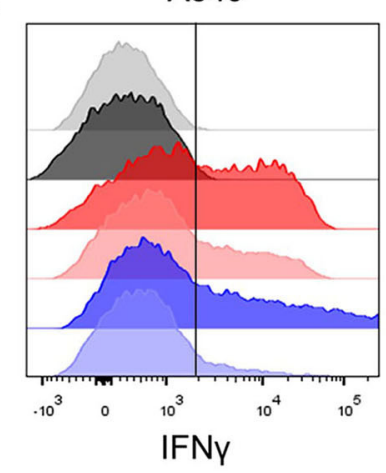

B Vy9Vס2 T cells

$100{ }_{7}$ expressing IFNy (\%)

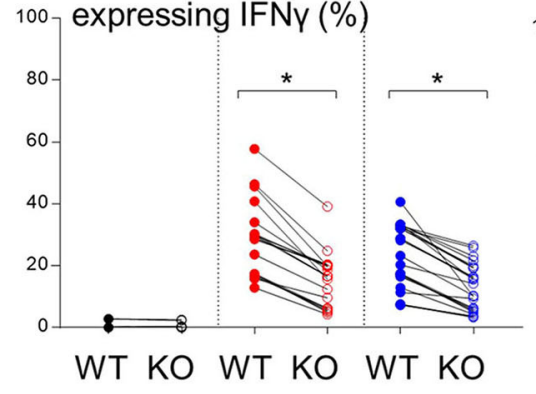

\section{c Vy9Vס2 T cells expressing PKH67 (\%)}

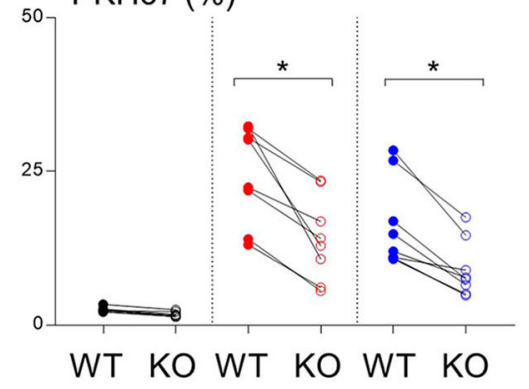

\section{E}

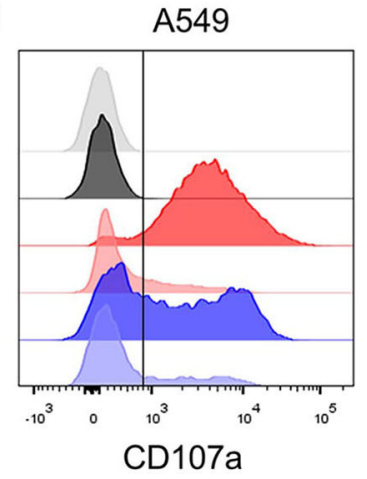

A549

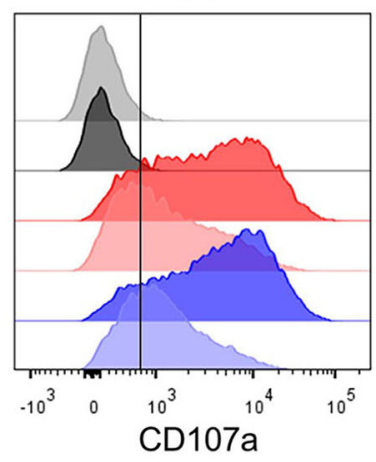

Ig

UT

Zol WT

Zol KO

BrHPP WT

BrHPP KO

Vү9Vס2 T cells expressing

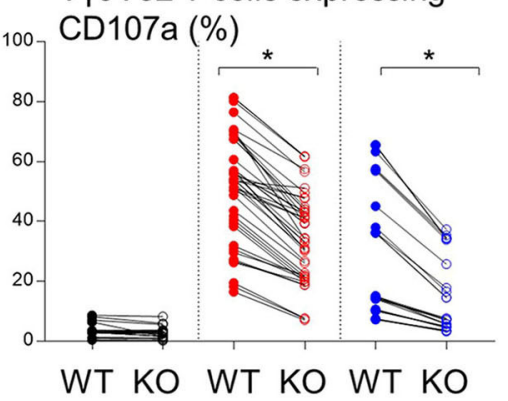

D

A549 7AAD ${ }^{+}(\%)$

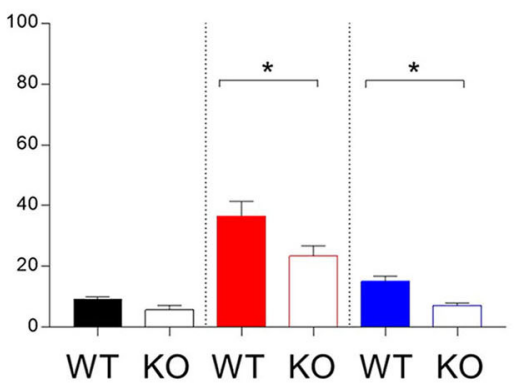

F

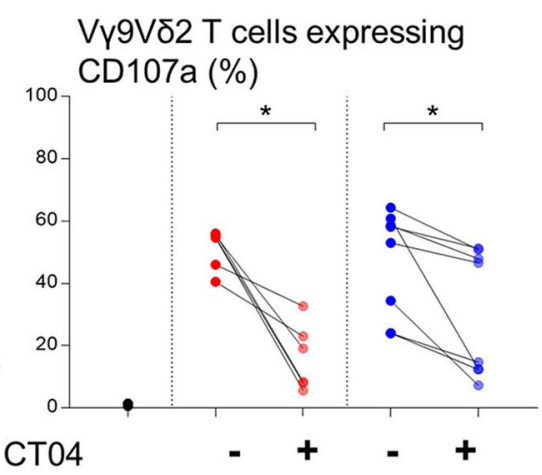

FIGURE 4 | Decrease of the V $\gamma 9$ V $82 T$ cells activation by A549 with RHOB knock down. Flow cytometry analysis of the IFN $\gamma$ and CD107a expression by V $\gamma 9 V \delta 2 T$ cells in co-culture for $4 \mathrm{~h}$ with A549 wild type (WT) or knock down for RHOB (KO) with zoledronate (red) or BrHPP (blue) pretreatment [(A): one representative experiment, (B): $n>10$ independent experiments]. (C) Flow cytometry analysis of the trogocytosis of the PKH67+ PAg-pretreated-A549 cell line WT or KO by the V $\gamma 9 V 82 \mathrm{~T}$ cells (ratio of the V $\gamma 9 \mathrm{~V} \delta 2 \mathrm{~T}$ cells expressing PKH67 $4 \mathrm{~h} / 5 \mathrm{~min}$ ). (D) Flow cytometry analysis of the 7AAD expression by the WT or KO A549 cell line PAg-treated (zoledronate: red, BrHPP: blue) or not (black) in co-culture for $4 \mathrm{~h}$ with the $\mathrm{V} \gamma 9 \mathrm{~V} \delta 2 \mathrm{~T}$ cells. (E,F) CD107a expression by the $\mathrm{V} \gamma 9 \mathrm{~V} \delta 2 \mathrm{~T}$ cells analyzed by flow cytometry after $4 \mathrm{~h}$ of contact with PAg-pretreated A549 in the presence or not of the CT04 inhibitor [(E): one representative experiment, (F): $n>4$ independent experiments]. *indicates $p<0.05$. 
A

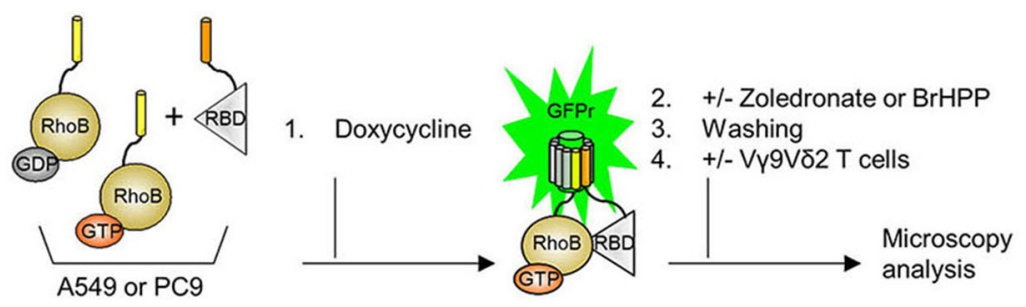

B
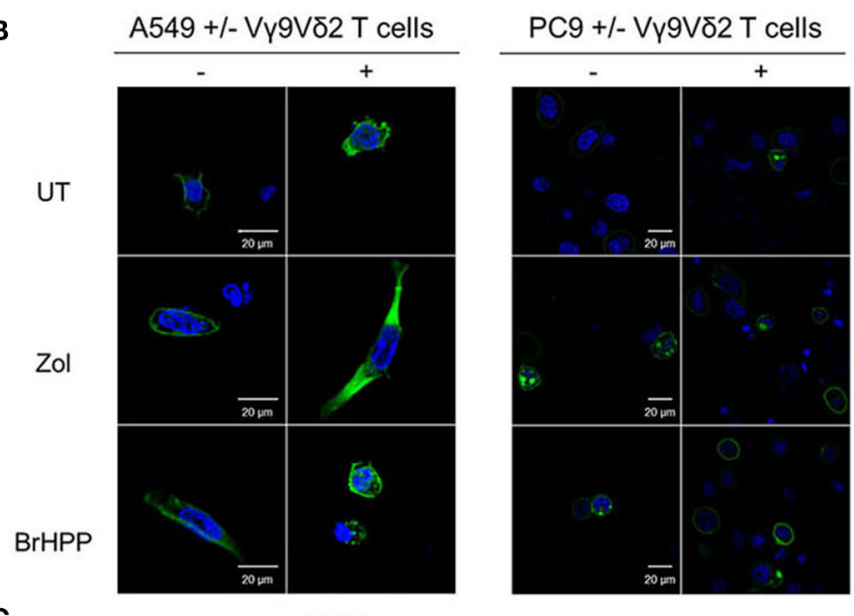

C

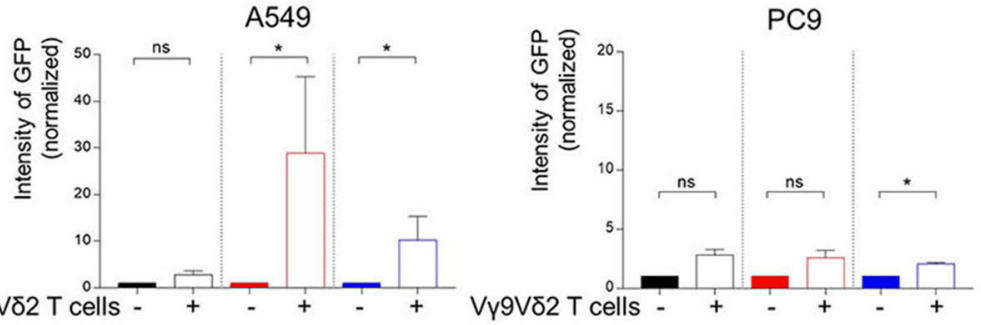

Vy9Vס2 T cells $-+{ }^{+}+$

D
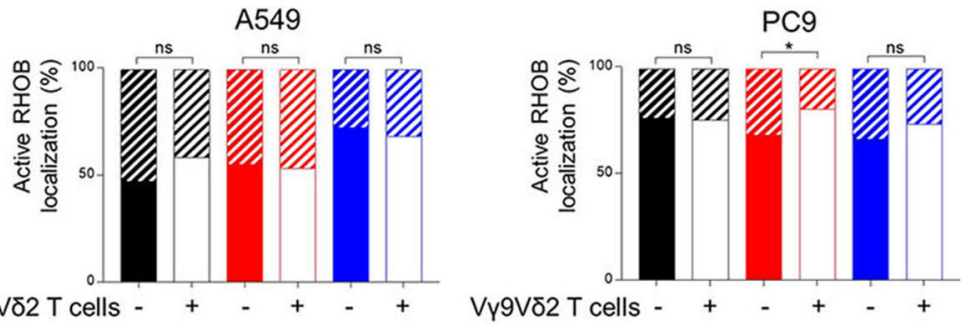

Vy9V82 T cells

Vy9Vס2 T cells -

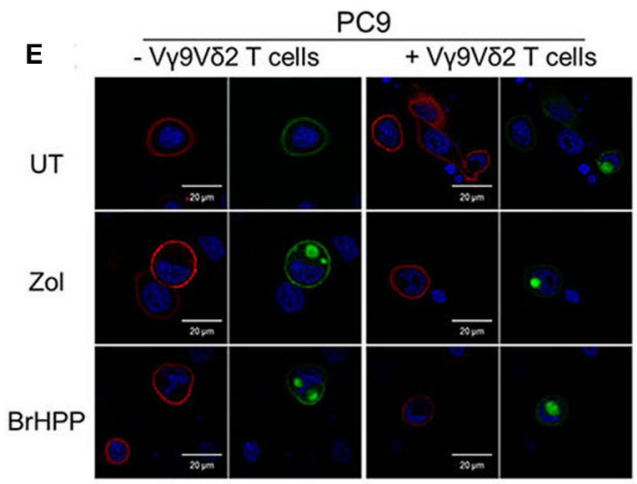

F
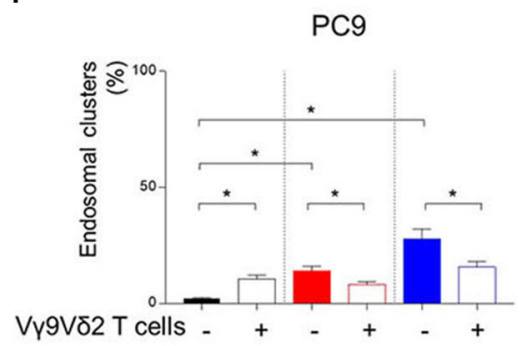

FIGURE 5 | Membrane localization of RHOB favored in A549 cells in contact with Vy9V82 T cells. (A) A549 and PC9 cells were engineered to stably express RHOB GTPase and monitor active RHOB using a split GFP system. Induction by Doxycycline of the tripartite split-GFP system in A549 and PC9, with or without (UT) pretreatment with zoledronate (zol) or BrHPP, and co-cultured or not with $\vee \gamma 9 \mathrm{~V} \delta 2 \mathrm{~T}$ cells. Active RHOB (green fluorescence) was visualized by confocal microscopy 
FIGURE 5 | (B) and quantified by Operetta [(C): zoledronate: red, BrHPP: blue]. (D) Percentage of endosomal (hatched bars) or membrane (full bars) active RHOB quantified by confocal microscopy in A549 and PC9 cell lines PAg-treated (zoledronate: red, BrHPP: blue) or not (black) co-cultured with V $\gamma 9 \mathrm{~V} \delta 2 \mathrm{~T}$ cells. (E,F) Confocal microscopy of total (red) and active (green) RHOB in PC9 cell line after PAg-treatment (zoledronate: red, BrHPP: blue) or not (black) and co-cultured or not with $V_{\gamma} 9 \mathrm{~V} \delta 2 \mathrm{~T}$ cells [(E): representative images; (F): \% of PC9 presenting endosomal clusters based on 3 independent experiments among 30 cells]. *indicates $p<$ 0.05 , Student's paired $t$-test; ns: no significant.

after co-culture with the PAg-treated RHOB KO A549 or the PAg-treated RHOB KO PC9. IFN $\gamma$ and CD107a expression by V $\gamma 9$ V $82 \mathrm{~T}$ cells was lower in the co-culture with A549 RHOB $\mathrm{KO}$ treated either by zoledronate or BrHPP compared to the co-culture with PAg-treated A549 wild type (WT) (Figure 4A for a representative experiment and Figure 4B for pooled experiments). Trogocytosis of A549 by $\mathrm{V} \gamma 9 \mathrm{~V} \delta 2 \mathrm{~T}$ cells was also reduced when RHOB was knocked down which was correlated with reduced death of A549 RHOB KO compared to A549 WT (Figures 4C,D).

Furthermore, we used a RHO GTPase inhibitor, the exoenzyme C3 transferase (CT04) that specifically inhibits RHOA, B, C. We showed that inhibition of RHO GTPases abrogated CD107a expression by $\mathrm{V} \gamma 9 \mathrm{~V} \delta 2 \mathrm{~T}$ cells in co-culture with A549 previously treated with zoledronate or BrHPP (Figure 4E for a representative experiment and Figure 4F for pooled experiments).

Moreover, the weak activation of $\mathrm{V} \gamma 9 \mathrm{~V} \delta 2 \mathrm{~T}$ cells by PAg-treated PC9 was also dependent on RHOB (Supplementary Figure 6).

\section{Rerouting of RHOB in Endosomal Clusters Could Impair the PAg-Dependent $\mathrm{V}_{\gamma} 9 \mathrm{~V} \delta 2 \mathrm{~T}$ Activation in PC9 Cells}

We then postulated that the PAg-treatment of tumor cell lines and/or their co-culture with $\mathrm{V} \gamma 9 \mathrm{~V} \delta 2 \mathrm{~T}$ cells could have an impact on RHOB activity using a fluorescent reporter based on the tripartite split-GFP system (22) which monitors the binding of activated RHOB to RBD, one of its effector domains (20). A549 and PC9 cells were engineered to stably express RHOB GTPase fused to strand 10 of trisfGFP (GFP10-RhoB) and the Rho-binding domain of Rhotekin (RBD) fused to strand 11 (RBD-11). The GFP1-9 detector fragment allows detection of the RHOB-GTP and RBD interaction (Figure 5A). Reporter cell lines were pre-treated with zoledronate ( $5 \mu \mathrm{M}$, overnight) or BrHPP $(1 \mu \mathrm{M}, 4 \mathrm{~h})$ and co-cultured or not with V $\gamma 9 \mathrm{~V} \delta 2 \mathrm{~T}$ cells. Treatment of A549 with these PAg induced and increased the number of fluorescent cells and their fluorescence intensity only in the presence of $\mathrm{V} \gamma 9 \mathrm{~V} \delta 2 \mathrm{~T}$ cells indicating a significant increase of RHOB activity in this tumor cell line (Figure 5B, representative images and Figure 5C quantification). Conversely, in PC9 cells, RHOB activity was not modulated by PAg treatment and slightly modulated in co-culture with $\mathrm{V} \gamma 9 \mathrm{~V} \delta 2 \mathrm{~T}$ cells, suggesting a different $\mathrm{RHOB}$ regulation mechanism in this cell line (Figures 5B,C). To take a closer look at RHOB function, we performed confocal imaging in untreated and PAg-treated conditions, in the presence or not of $\mathrm{V} \gamma 9 \mathrm{~V} \delta 2 \mathrm{~T}$ cells and we analyzed the distribution of active RHOB (Figure 5D, membrane localization full bars and endosomal localization hatched bars).
Surprisingly, active RHOB was significantly twice as abundant in the endosomal compartment of A549 cells compared to PC9 cells (Figure 5D, quantification). High resolution microscopy allowed us to analyze endosomal organization in PC9. Untreated reporter PC9 showed faint plasma membrane localization of RHOB/RBD complexes. Interestingly, treatment with zoledronate or BrHPP induced an accumulation of large endosomal clusters (Figure $5 \mathrm{E}$, representative images). Quantification of the number of these structures indicated an increase of activated RHOB located in endosomal clusters in PAg-treated PC9 co-cultured or not with $\mathrm{V} \gamma 9 \mathrm{~V} \delta 2 \mathrm{~T}$ cells (Figure 5F). These endosomal clusters were reported randomly in PC 9 cells co-cultured with V $\gamma 9 \mathrm{~V} \delta 2 \mathrm{~T}$ cells independently of the treatment. Interestingly, these endosomal structures did not appear in the PAg-treated A549 co-cultured or not with $\mathrm{V} \gamma 9 \mathrm{~V} \delta 2 \mathrm{~T}$ cells (Supplementary Figure 7), suggesting that this endosomal reorganization was not due to the treatment with P-Ag mevalonate inhibitors. To identify the nature of these structures, we analyzed the localization of activated RHOB with different endosomal markers. Representative images and plot profile analysis on confocal stacks indicated a co-localization partly with late endosomal marker Rab7 and to a lesser extend with the LAMP1 lysosomal marker only after PAg-treated PC9 were co-cultured with $\mathrm{V} \gamma 9 \mathrm{~V} \delta 2 \mathrm{~T}$ cells independently of the treatment (Figure 6). These results indicate that in PC9 cells, endosomal $\mathrm{RHOB}$ is located in the late endosomal and on route to the lysosomal compartment.

\section{DISCUSSION}

The anti-tumor effect of $\mathrm{V} \gamma 9 \mathrm{~V} \delta 2 \mathrm{~T}$ cells depends on the phosphoantigens expressed by tumor cells but also on certain activator ligands (MICA/B and ULBPs) and adhesion molecules, essential to stabilize the immunological synapse. As PAg is not expressed by all tumor cells, treatment with exogenous PAg such as BrHPP or with aminobisphosphonates which induce endogenous PAg production such as isopentenyl pyrophosphate (IPP), is required to activate the anti-tumor functions of $\mathrm{V} \gamma 9 \mathrm{~V} \delta 2 \mathrm{~T}$ cells. However, $\mathrm{V} \gamma 9 \mathrm{~V} \delta 2 \mathrm{~T}$ cell activation can also be lowered by inhibitory signals that can be expressed by the tumor microenvironment and in particular by tumor cells. In this study, none of the NSCLC cell lines were able to spontaneously activate $\mathrm{V} \gamma 9 \mathrm{~V} \delta 2 \mathrm{~T}$ cells. However, pre-treatment with BrHPP or zoledronate sensitized some of them to $\mathrm{V} \gamma 9 \mathrm{~V} \delta 2 \mathrm{~T}$ cell killing. Indeed, amongst them, A549 was able to strongly activate IFN $\gamma$ and CD107a expression by V $\gamma 9 \mathrm{~V} \delta 2 \mathrm{~T}$ cells whereas PC9 induced a weak activation of these lymphocytes. Interestingly, these two cell lines express RHOB but wear different mutation, KRAS for A549 and EGFR for PC9. However, nothing was described 

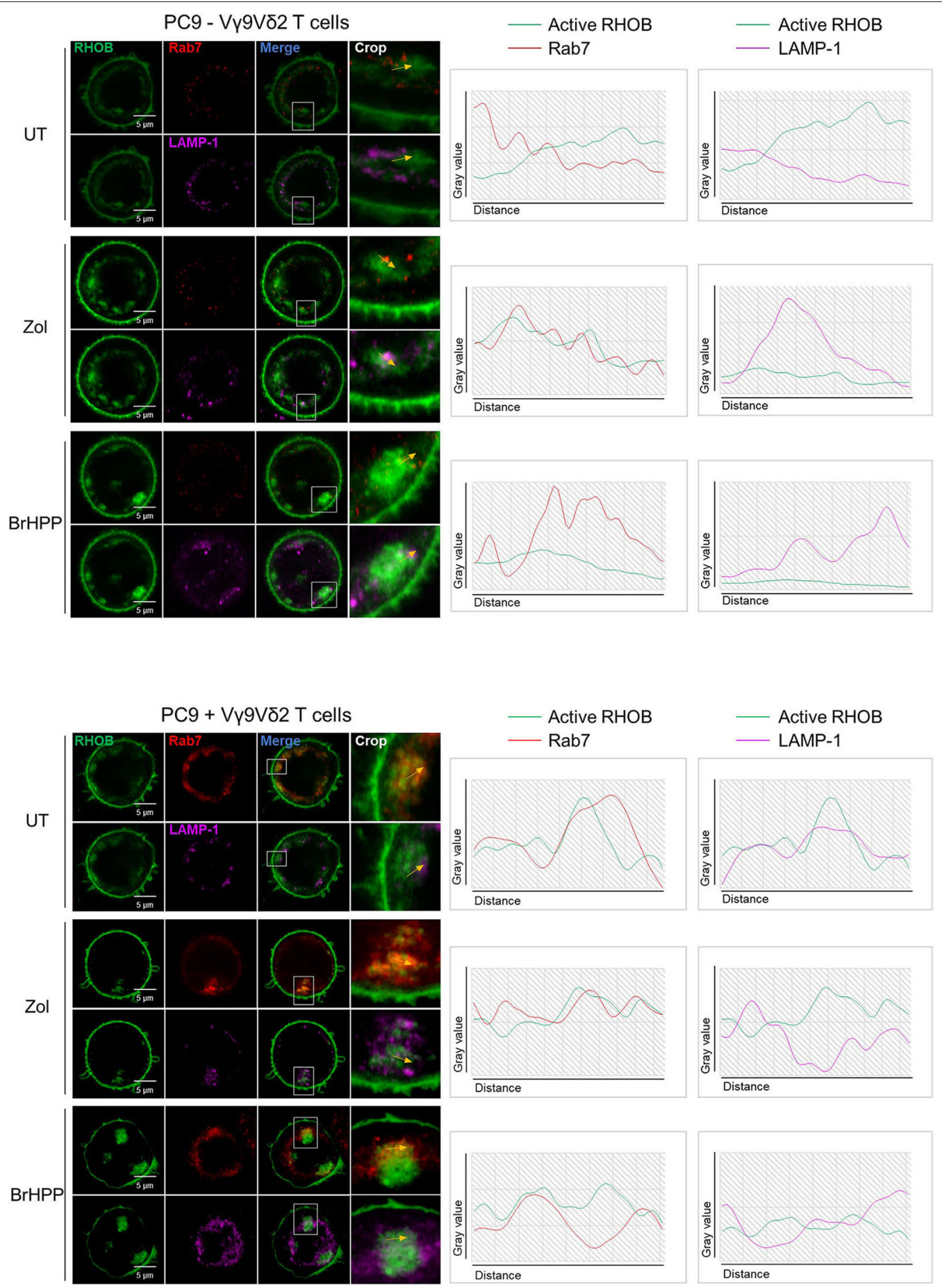

FIGURE 6 | Rerouting of RHOB in endosomal clusters in PAg-treated PC9 cells in contact with V $\gamma 9 \mathrm{~V} \delta 2 \mathrm{~T}$ cells. Co-localization analysis by confocal microscopy of active RHOB (green), Rab7 (red) for late endosome/MVB marker and LAMP-1 (pink) as lysosomal marker, in PC9 cells pre-treated or not (UT) with zoledronate (zol) or BrHPP, and co-cultured (lower) or not (upper) with $\vee \gamma 9 \mathrm{~V} \delta 2 \mathrm{~T}$ cells (representative image, crop on the key zone, and plot profile analysis beside showed by yellow arrows).

concerning some phenotypic specificities which could explain the different sensitivity of these cells toward $\mathrm{V} \gamma 9 \mathrm{~V} \delta 2 \mathrm{~T}$ killers.

Surprisingly, exploring their surface molecule pattern, we showed that these two NSCLC cell lines could differentially express NKG2D ligands, immune checkpoint ligands, and adhesion molecules. PC9 highly expressed ICAM-1, ULBPs, and PDL1 whereas A549 highly expressed CD38 and HLAA,B,C, the two cell lines expressed LFA-1, LFA-3, and CD155 
but not ICAM-3, CD112, MICA/B, HLA-E, or galectin-9. The presence of ULBPs ligands could partially explain the reactivity of $\mathrm{V} \gamma 9 \mathrm{~V} \delta 2 \mathrm{~T}$ cells against NSCLC cell lines. However, blocking NKG2D expressed at the surface of $\mathrm{V} \gamma 9 \mathrm{~V} \delta 2 \mathrm{~T}$ did not decrease their activation which is thus only induced here by PAg and not by other activator ligands. Furthermore, we showed that blocking of ICAM-3/LFA-3 decreased the cytolytic activity of $\mathrm{V} \gamma 9 \mathrm{~V} \delta 2 \mathrm{~T}$ against A549 and blocking of ICAM1/LFA-1 decreased this activity against PC9. For these two cell lines, stabilization of the immunological synapse around TCR/BTN3A1 is thus coordinated by two different adhesion systems. If LFA-1 engagement by ICAM-1 is sufficient to activate iNKT cells (23) in this model of lung cancer/V $\gamma 9 \mathrm{~V} \delta 2 \mathrm{~T}$, interactions of adhesion molecules are not sufficient to induce an activating signaling in $\mathrm{V} \gamma 9 \mathrm{~V} \delta 2 \mathrm{~T}$ cells. However, according to the literature, these interactions are necessary when their inhibition highly decreases $\mathrm{V} \gamma 9 \mathrm{~V} \delta 2 \mathrm{~T}$ activation $(9,24)$. But this does not explain the difference between A549 and PC9. First, we thought that the high expression of PDL1 by PC9 could explain the inhibition of $\mathrm{V} \gamma 9 \mathrm{~V} \delta 2 \mathrm{~T}$ activation. However, PD1 blocking did not induce an increase in CD107a or IFN $\gamma$ expression by $\mathrm{V} \gamma 9 \mathrm{~V} \delta 2 \mathrm{~T}$ cells. As surface inhibitor markers were not at the origin of the weak activation of $\mathrm{V} \gamma 9 \mathrm{~V} \delta 2 \mathrm{~T}$ cells, we focused on RHOB inside the cells. According to the literature (18) and thanks to NSCLC cell lines with a RHOB KO, we showed that $\mathrm{RHOB}$ was involved in the $\mathrm{V} \gamma 9 \mathrm{~V} \delta 2 \mathrm{~T}$ activation through endogenous PAg induced by a zoledronate treatment but also through exogenous PAg such as BrHPP. The non-reactivity of V $\gamma 9 \mathrm{~V} 82 \mathrm{~T}$ cells with the conditioned medium of BrHPP pretreated tumor cells or in co-culture with these cells separated by a porous membrane (Transwell), demonstrated that BrHPP was able to penetrate inside the tumor cell and to activate membrane BTN3A1 shown to be essential for this activation (19). RHOB is thus also involved in the activation of $\mathrm{V} \gamma 9 \mathrm{~V} \delta 2 \mathrm{~T}$ cells through the exogenous PAg, BrHPP. Interestingly, the ICAM1 signaling cascade is also highly dependent on RHO proteins, as ICAM-1 crosslinking induces actin reorganization which involves RHOB proteins (25). PC9 expresses a high amount of ICAM-1 which is involved in the immunological synapse with V $\gamma 9 \mathrm{~V} \delta 2 \mathrm{~T}$ but does not efficiently activate the latter. To explain the weak reactivity of $\mathrm{V} \gamma 9 \mathrm{~V} \delta 2 \mathrm{~T}$ cells against PAg-pretreated PC9, we examined RHOB activity and its localization. The similar reactivity of $\mathrm{V} \gamma 9 \mathrm{~V} \delta 2 \mathrm{~T}$ cells against A549 and PC9 pulsed with the 20.1 BTN3A1 agonist (Supplementary Figure 8) supports the important role of $\mathrm{RHOB}$ in the PAg-induced response in this model. Our results show that active RHOB is localized in endosomes and at the plasma membrane of both A549 and PC9 cell lines. This is in agreement with previous reports of GFPRHOB fusions in human epithelial cells (26). Our results indicate that active RHOB is increased in PAg-treated A549 cells cocultured with $\mathrm{V} \gamma 9 \mathrm{~V} \delta 2 \mathrm{~T}$ cells, whereas only a slight increase of active RHOB is observed in PC9 cells co-cultured with V $\gamma 9 \mathrm{~V} \delta 2 \mathrm{~T}$ cells independently of PAg treatment. It is important to note that the activation of RhoB in co-culture of A549 and V $\gamma 9 \mathrm{~V} \delta 2 \mathrm{~T}$ is mainly dependent on the treatment by the PAg (Figure 5C). It has been previously established that treatment with PAg induces an increase of active RHOB that will modify the conformation of the
BTN3A1 at the plasma membrane, which allows the activation of $\mathrm{V} \gamma 9 \mathrm{~V} \delta 2 \mathrm{~T}$ cells (18). The fact that the presence of $\mathrm{V} \gamma 9 \mathrm{~V} \delta 2 \mathrm{~T}$ cells further increases RHOB activity suggests that RHOB may be activated by exogenous stress signals and cytokines that would come from activated $\mathrm{V} \gamma 9 \mathrm{~V} \delta 2 \mathrm{~T}$ cells. Indeed, in other contexts involving immune cells, RHOB has been shown to be upregulated by environmental stress, cytokines, and LPS, and regulating this latter signaling (27-29). Our hypothesis would be that signals secreted by activated $\mathrm{V} \gamma 9 \mathrm{~V} \delta 2 \mathrm{~T}$ cells would contribute to RHOB activation in a cooperative manner with PAg. These results corroborate with the $\mathrm{V} \gamma 9 \mathrm{~V} \delta 2 \mathrm{~T}$ cell activation observed with A549 or -PC9 treated with PAg (Figure 1 and Supplementary Figure 1). Altogether this indicates that the reactivity of these cell lines is strongly linked to RHOB function. In terms of subcellular localization, both cell lines contain active RHOB at the plasma membrane, with a stronger distribution in PC9 cells. A higher proportion of active RHOB is present in the endosomal compartment in A549 compared to PC9, however they differ strongly in terms of endosomal distribution. Whereas in A549, endosomal RHOB is diffusely distributed, in PC9 endosomal active RHOB was found in large clusters that co-localized with late Rab7 endosomal and LAMP-1 lysosomal markers. It is known that $\mathrm{V} \gamma 9 \mathrm{~V} \delta 2 \mathrm{~T}$ cell activation occurs at the plasma membrane through the involvement of BTN3A1 that is addressed by RHOB vesicles from the endosomes to the plasma membrane (18). In our model, PAg treatment of PC9 cells is not sufficient to trigger an increase in $\mathrm{RHOB}$ activation but requires the contact with $\mathrm{V} \gamma 9 \mathrm{~V} \delta 2 \mathrm{~T}$ cells, as untreated conditions in the presence of $\mathrm{V} \gamma 9 \mathrm{~V} \delta 2 \mathrm{~T}$ cells did not induce a significant increase in $\mathrm{RHOB}$ activity. One hypothesis of the weaker activation of RHOB in PC9 cells is that beyond the mode of recognition with $\mathrm{T}$ cells, the organization of endosomal RHOB-mediated signaling is not efficient for addressing important signaling molecules such as BTN3A1 at the plasma membrane. It was reported that $\mathrm{RHOB}$ interacts with the intracellular domain of BTN3A1 at the plasma membrane (18). BTN3A1 was shown as essential to $\mathrm{V} \gamma 9 \mathrm{~V} \delta 2 \mathrm{~T}$ cell recognition but not sufficient for this process as its homologous BTN2A1, the phosphoantigens being also essential. Actually, it was recently described that BTN2A1 synergized with BTN3A1 in sensitizing PAg-exposed cells for V $\gamma 9 \mathrm{~V} 82$ TCRmediated responses, these two butyrophilins beings key ligands that bind possibly two different domains of this TCR $(30,31)$. As for BTN3A1, the level of expression of BTN2A1 mRNA in PC9 is very close to that in A549 (Supplementary Figure 9). Thus, we can expect that these two cell lines express a similar level of BTN2A1 at their membrane, the BNT3A1 expression being equivalent (Figure 3B). Therefore, the weak activation of the V $\gamma 9 \mathrm{~V} 82 \mathrm{~T}$ cell by the PC9 cell line should not be due to the lack of BTN2A1. RHOB has not yet been shown to be associated to the intracellular B30.2 domain of the BTN2A1. Actually, it could be interesting to know if RHOB, as for BNT3A1, can be involved in the modification of the conformation of the BTN2A1. The organization of endosomal RHOB could then have an impact also on the BTN2A1. Further investigations should be pursued to evaluate whether such a mechanism is preserved in PC9. This endosomal signaling could be favored due to the genetic background of these cells, i.e., as they express an activated 
EGFR mutant whose expression may modify intracellular RHOB mediated trafficking. Indeed, $\mathrm{RHOB}$ is known to prolong endosomal signaling of EGFR following its internalization (32). RHOB is a short-lived protein that is rapidly degraded through the endo-lysosomal pathway (33) and its degradation is delayed by inhibition of its isoprenylation. Treatment with PAg, while necessary for the activation of $\mathrm{V} \gamma 9 \mathrm{~V} \delta 2 \mathrm{~T}$ cells, contributes to a rerouting of $\mathrm{RHOB}$ in late/degradation compartments that may accelerate its degradation and prevent its function in endocytic trafficking to the plasma membrane in PC9 cells.

This study demonstrates for the first time that $\mathrm{V} \gamma 9 \mathrm{~V} \delta 2 \mathrm{~T}$ cell activation by PAg-treated tumor cells can be variable depending on several factors such as oncogenic mutation, RHOB activity, and surface markers. Our results indicate that this response is strongly influenced by RHOB function. Therefore, the regulation of endocytic traffic by RHOB in the tumor cell could be decisive for the immune response and may explain the resistance of some tumor cells that nevertheless highly express RHOB.

\section{DATA AVAILABILITY STATEMENT}

The datasets presented in this study can be found in online repositories. The names of the repository/repositories and accession number(s) can be found below: https://portals. broadinstitute.org/ccle/data, CCLE.

\section{AUTHOR'S NOTE}

The precise mechanism of $\mathrm{V} \gamma 9 \mathrm{~T}$ cells phosphoantigen (PAg)activation remains elusive even the butyrophilin BTN3A and the RHOB GTPase are known as essential in this activation. RHOB which can have a dualistic role in cancer, was shown as conferring resistance to EGFR-tyrosine kinase inhibitors in

\section{REFERENCES}

1. Kabelitz D, Wesch D, Pitters E, Zöller M. Characterization of tumor reactivity of human $\mathrm{V}$ gamma 9V delta 2 gamma delta T cells in vitro and in SCID mice in vivo. J Immunol. (2004) 173:6767-76. doi: 10.4049/jimmunol.173.11.6767

2. Poupot M, Fournié J-J. Non-peptide antigens activating human Vgamma9/Vdelta2 T lymphocytes. Immunol Lett. (2004) 95:12938. doi: 10.1016/j.imlet.2004.06.013

3. Gober H-J, Kistowska M, Angman L, Jenö P, Mori L, de Libero G. Human T cell receptor gammadelta cells recognize endogenous mevalonate metabolites in tumor cells. J Exp Med. (2003) 197:163-8. doi: 10.1084/jem.200 21500

4. Hebbeler AM, Cairo C, Cummings JS, Pauza CD. Individual Vgamma2Jgamma1.2+ $\mathrm{T}$ cells respond to both isopentenyl pyrophosphate and Daudi cell stimulation: generating tumor effectors with low molecular weight phosphoantigens. Cancer Immunol Immunother CII. (2007) 56:81929. doi: 10.1007/s00262-006-0235-6

5. Roelofs AJ, Jauhiainen M, Mönkkönen H, Rogers MJ, Mönkkönen J, Thompson K. Peripheral blood monocytes are responsible for gammadelta $\mathrm{T}$ cell activation induced by zoledronic acid through accumulation of IPP/DMAPP. Br J Haematol. (2009) 144:245-50. doi: 10.1111/j.1365-2141.2008.07435.x

6. Rossi C, Gravelle P, Decaup E, Bordenave J, Poupot M, Tosolini M, et al. Boosting $\gamma \delta \mathrm{T}$ cell-mediated antibody-dependent cellular cytotoxicity lung cancer and frequently downregulated in aggressive lung cancer. Besides, V $\gamma 9 \mathrm{~T}$ cells based therapies could be an issue for advanced lung cancers refractory to or intolerant of current conventional treatment. The role of RHOB in the PAg-activation of $\mathrm{V} \gamma 9 \mathrm{~T}$ cells in lung cancer has to be depicted when $\mathrm{V} \gamma 9 \mathrm{~T}$ cells reactivity depends on the lung tumor cell lines status.

\section{AUTHOR CONTRIBUTIONS}

CLap, SM, MM, and SF performed the experiments. SF and OC performed the KO cell lines. SC, OC, J-JF, GF, and CLau participated to the discussion of the results. MP and SC designed experiments and wrote the manuscript. MP supervised the study. All authors contributed to the article and approved the submitted version.

\section{FUNDING}

This work was funded by INSERM, CNRS, the University Hospital of Bordeaux and Toulouse III University.

\section{ACKNOWLEDGMENTS}

We are grateful to our healthcare professionals for their boundless investment during the COVID-19 crisis. We acknowledge ImCheck Therapeutics for giving us the 103.2 antibody. We acknowledge the Technologic Platform of the CRCT.

\section{SUPPLEMENTARY MATERIAL}

The Supplementary Material for this article can be found online at: https://www.frontiersin.org/articles/10.3389/fimmu. 2020.01396/full\#supplementary-material

by PD-1 blockade in follicular lymphoma. Oncoimmunology. (2019) 8:1554175. doi: 10.1080/2162402X.2018.1554175

7. Girard P, Charles J, Cluzel C, Degeorges E, Manches O, Plumas J, et al. The features of circulating and tumor-infiltrating $\gamma \delta \mathrm{T}$ cells in melanoma patients display critical perturbations with prognostic impact on clinical outcome. Oncoimmunology. (2019) 8:1601483. doi: 10.1080/2162402X.2019.1601483

8. Groh V, Rhinehart R, Secrist H, Bauer S, Grabstein KH, Spies T. Broad tumor-associated expression and recognition by tumor-derived gamma delta T cells of MICA and MICB. Proc Natl Acad Sci USA. (1999) 96:687984. doi: 10.1073/pnas.96.12.6879

9. Corvaisier M, Moreau-Aubry A, Diez E, Bennouna J, Mosnier J-F, Scotet E, et al. V $\gamma 9 \mathrm{~V} \delta 2 \mathrm{~T}$ cell response to colon carcinoma cells. J Immunol. (2005) 175:5481-8. doi: 10.4049/jimmunol.175.8.5481

10. Fournié J-J, Sicard H, Poupot M, Bezombes C, Blanc A, Romagné F, et al. What lessons can be learned from $\gamma \delta$ T cell-based cancer immunotherapy trials? Cell Mol Immunol. (2013) 10:35-41. doi: 10.1038/cmi.2012.39

11. Casetti R, Perretta G, Taglioni A, Mattei M, Colizzi V, Dieli F, et al. Drug-induced expansion and differentiation of $\mathrm{V} \gamma 9 \mathrm{~V} \delta 2 \mathrm{~T}$ cells in vivo: the role of exogenous IL-2. J Immunol. (2005) 175:1593-8. doi: 10.4049/jimmunol.175.3.1593

12. Sicard H, Ingoure S, Luciani B, Serraz C, Fournié J-J, Bonneville M, et al. In vivo immunomanipulation of $\mathrm{V} \gamma 9 \mathrm{~V} \delta 2 \mathrm{~T}$ cells with a synthetic phosphoantigen in a preclinical nonhuman primate model. J Immunol. (2005) 175:5471-80. doi: 10.4049/jimmunol.175.8.5471 
13. Izumi H, Yamasaki A, Takeda K, Kodani M, Touge H, Tanaka N, et al. Acutephase reaction induced by zoledronate and its effect on prognosis of patients with advanced non-small cell lung cancer. Lung Cancer Amst Neth. (2018) 122:200-5. doi: 10.1016/j.lungcan.2018.06.022

14. Kakimi K, Matsushita H, Murakawa T, Nakajima J. $\gamma \delta \mathrm{T}$ cell therapy for the treatment of non-small cell lung cancer. Transl Lung Cancer Res. (2014) 3:23-33. doi: 10.3978/j.issn.2218-6751.2013.11.01

15. Mazieres J, Antonia T, Daste G, Muro-Cacho C, Berchery D, Tillement V, et al. Loss of RhoB expression in human lung cancer progression. Clin Cancer Res Off J Am Assoc Cancer Res. (2004) 10:2742-50. doi: 10.1158/1078-0432.CCR-03-0149

16. Calvayrac O, Pradines A, Raymond-Letron I, Rouquette I, Bousquet E, Lauwers-Cances V, et al. RhoB determines tumor aggressiveness in a murine EGFRL858R-induced adenocarcinoma model and is a potential prognostic biomarker for Lepidic lung cancer. Clin Cancer Res. (2014) 20:654150. doi: 10.1158/1078-0432.CCR-14-0506

17. Calvayrac O, Mazières J, Figarol S, Marty-Detraves C, RaymondLetron I, Bousquet E, et al. The RAS-related GTPase RHOB confers resistance to EGFR-tyrosine kinase inhibitors in non-small-cell lung cancer via an AKT-dependent mechanism. EMBO Mol Med. (2017) 9:238-50. doi: 10.15252/emmm.201606646

18. Sebestyen Z, Scheper W, Vyborova A, Gu S, Rychnavska Z, Schiffler M, et al. RhoB mediates phosphoantigen recognition by $\mathrm{V} \gamma 9 \mathrm{~V} \delta 2 \mathrm{~T}$ cell receptor. Cell Rep. (2016) 15:1973-85. doi: 10.1016/j.celrep.2016.04.081

19. Harly C, Guillaume Y, Nedellec S, Peigné C-M, Mönkkönen H, Mönkkönen J, et al. Key implication of CD277/butyrophilin-3 (BTN3A) in cellular stress sensing by a major human $\gamma \delta$ T-cell subset. Blood. (2012) 120:226979. doi: 10.1182/blood-2012-05-430470

20. Koraïchi F, Gence R, Bouchenot C, Grosjean S, Lajoie-Mazenc I, Favre G, et al. High-content tripartite split-GFP cell-based assays to screen for modulators of small GTPase activation. J Cell Sci. (2018) 131:jcs210419. doi: 10.1242/jcs.210419

21. Rothbauer U, Zolghadr K, Muyldermans S, Schepers A, Cardoso MC, Leonhardt $\mathrm{H}$. A versatile nanotrap for biochemical and functional studies with fluorescent fusion proteins. Mol Cell Proteomics MCP. (2008) 7:2829. doi: 10.1074/mcp.M700342-MCP200

22. Cabantous S, Nguyen HB, Pedelacq J-D, Koraïchi F, Chaudhary A, Ganguly K, et al. A new protein-protein interaction sensor based on tripartite split-GFP association. Sci Rep. (2013) 3:2854. doi: 10.1038/srep02854

23. Sharma A, Lawry SM, Klein BS, Wang X, Sherer NM, Zumwalde NA, et al. LFA-1 ligation by high-density ICAM-1 is sufficient to activate IFN- $\gamma$ release by innate T lymphocytes. J Immunol. (2018) 201:245261. doi: 10.4049/jimmunol.1800537

24. Liu Z, Guo B, Lopez RD. Expression of intercellular adhesion molecule (ICAM)-1 or ICAM-2 is critical in determining sensitivity of pancreatic cancer cells to cytolysis by human gammadelta-T cells: implications in the design of gammadelta-T-cell-based immunotherapies for pancreatic cancer. J Gastroenterol Hepatol. (2009) 24:900-11. doi: 10.1111/j.1440-1746.2008.05668.x

25. Etienne-Manneville S, Manneville JB, Adamson P, Wilbourn B, Greenwood J, Couraud PO. ICAM-1-coupled cytoskeletal rearrangements and transendothelial lymphocyte migration involve intracellular calcium signaling in brain endothelial cell lines. J Immunol. (2000) 165:3375-83. doi: 10.4049/jimmunol.165.6.3375

26. Wherlock M, Gampel A, Futter C, Mellor H. Farnesyltransferase inhibitors disrupt EGF receptor traffic through modulation of the RhoB GTPase. J Cell Sci. (2004) 117:3221-31. doi: 10.1242/jcs.01193

27. Kamon H, Kawabe T, Kitamura H, Lee J, Kamimura D, Kaisho T, et al. TRIF-GEFH1-RhoB pathway is involved in MHCII expression on dendritic cells that is critical for CD4 T-cell activation. EMBO J. (2006) 25:410819. doi: $10.1038 /$ sj.emboj.7601286

28. Ocana-Morgner C, Wahren C, Jessberger R. SWAP-70 regulates RhoA/RhoBdependent MHCII surface localization in dendritic cells. Blood. (2009) 113:1474-82. doi: 10.1182/blood-2008-04-152587

29. Liu S, Huang L, Lin Z, Hu Y, Chen R, Wang L, et al. RhoB induces the production of proinflammatory cytokines in TLR-triggered macrophages. Mol Immunol. (2017) 87:200-6. doi: 10.1016/j.molimm.2017. 04.015

30. Rigau M, Ostrouska S, Fulford TS, Johnson DN, Woods K, Ruan $\mathrm{Z}$, et al. Butyrophilin $2 \mathrm{~A} 1$ is essential for phosphoantigen reactivity by $\gamma \delta \mathrm{T}$ cells. Science. (2020) 367:eaay5516. doi: 10.1126/science. aay5516

31. Karunakaran MM, Willcox CR, Salim M, Paletta D, Fichtner AS, Noll A, et al. Butyrophilin-2A1 directly binds germline-encoded regions of the $\mathrm{V} \gamma 9 \mathrm{~V} \delta 2$ TCR and is essential for phosphoantigen sensing. Immunity. (2020) 52:48798.e6. doi: 10.1016/j.immuni.2020.02.014

32. Gampel A, Parker PJ, Mellor H. Regulation of epidermal growth factor receptor traffic by the small GTPase rhoB. Curr Biol CB. (1999) 9:9558. doi: 10.1016/S0960-9822(99)80422-9

33. Pérez-Sala D, Boya P, Ramos I, Herrera M, Stamatakis K. The C-terminal sequence of RhoB directs protein degradation through an endo-lysosomal pathway. PLoS ONE. (2009) 4:e8117. doi: 10.1371/journal.pone.0008117

Conflict of Interest: The authors declare that the research was conducted in the absence of any commercial or financial relationships that could be construed as a potential conflict of interest.

Copyright (C) 2020 Laplagne, Meddour, Figarol, Michelas, Calvayrac, Favre, Laurent, Fournié, Cabantous and Poupot. This is an open-access article distributed under the terms of the Creative Commons Attribution License (CC BY). The use, distribution or reproduction in other forums is permitted, provided the original author(s) and the copyright owner(s) are credited and that the original publication in this journal is cited, in accordance with accepted academic practice. No use, distribution or reproduction is permitted which does not comply with these terms. 